\title{
A spatial framework for detecting anthropogenic impacts on predator-prey interactions that sustain ecological integrity in Mexico
}

Franz Mora

\begin{abstract}
Background: This paper presents several spatial indicators developed to evaluate anthropogenic impacts on predator-prey interactions and their relationship with ecological integrity loss in Mexico. Ecological integrity loss is defined as the inability to sustain viable populations, habitat functions, and species interactions of Nearctic and Neotropical apex predators as a result of anthropogenic effects. As direct impacts, the indicators evaluate habitat loss and the number of inhospitable habitats. As indirect impacts, the indicators evaluate the avoidance of human features such as highways, roads, and human locations. The total impact level is described at $1 \mathrm{~km}^{2}$ resolution, and registered within the domain defined by the spatial habitat requirements of apex predators. The impact level is associated with ecological integrity loss, or the ecosystem capacity to reorganize habitat functions and sustain predator-prey interactions as the most visible elements of ecological integrity. Ecological integrity loss is evaluated for different groups of apex predators that are classified with different levels of anthropogenic threat.

Results: The framework presented here identifies the spatial information needed for the assessment of cumulative anthropogenic impacts. By characterizing their distribution range, Nearctic predators have significantly larger intact habitats than neotropical predators but with higher ecological degradation, less landscape transformation, and overall less ecological integrity. As observed within their distribution areas, indirect impacts have a generalized effect in the broad range of landscapes in Mexico. Ecological integrity loss is the result of road, highway, and human settlement avoidance; but landscape transformation and human activity control the threshold for which ecological integrity loss becomes critical. On the other hand, there are no significant differences in impact levels among threat conservation categories for apex predators, which indicate that all predator species have the same threat level and should be all included in protection efforts.

Conclusions: With the application of this spatial framework, the significance, scale, and baseline conditions can be established for evaluating anthropogenic impacts on ecological integrity. The analysis of the current condition shows the status for apex predator in the country, and identifies the ecological integrity threshold when human activities have severe to highly severe impacts in the landscape, threatening the viability of populations and their habitat.
\end{abstract}

Keywords: Anthropogenic impacts, Ecological integrity, Spatial indicators, Apex predators, Impact assessment 


\section{Introduction}

The use of reliable biodiversity indicators that describe the state of ecosystems in a factual and responsive manner to set conservation efforts is one of the major goals of the Convention of Biological Diversity (Dobson 2005; Dobson et al. 2011). Thus, biodiversity indicators have gone from simple metrics that measure the diversity of organisms toward more comprehensive monitoring measures that indicate the state of ecosystems (Callicott and Mumford 1997; Cowell 1998; Reza and Abdullah 2011; Capmourteres and Anand 2016; Rempel et al. 2016; Roche and Campagne 2017). Within ecological monitoring frameworks, ecological integrity (EI) is a key concept for evaluating ecosystem condition (Thompson 1999; Tierney et al. 2009; Brown and Williams 2016). Previously defined, ecological integrity is "the capacity of the ecosystem to support and maintain a balanced, integrated, adaptive biological system having the full range of elements and processes expected in the natural habitat of a region" (Karr 1990; Angermeier and Karr 1994; Parrish et al. 2003), and therefore, it is directly associated with the current knowledge of ecosystem functioning (Jax 2010).

With landscape transformation targeting natural remnant areas, human activity threatens ecological systems, as anthropogenic impacts are often observed as a loss of ecological integrity. The transformation of the natural landscape by humans is still the main direct driver of habitat fragmentation and species loss which directly affects ecosystem organization and function (Sih et al. 2000; Ewers et al. 2010; Swift and Hannon 2010), and indirectly hinders ecosystem functioning by restricting animal movement and habitat use (Tucker et al. 2018). Habitat loss and consequent fragmentation are still the main causes that degrade ecological integrity by modifying key ecological processes such as biotic (e.g., predator-prey) and abiotic interactions (Ripple and Beschta 2004; Miller et al. 2012) and by producing negative effects on wildlife habitats (Crooks et al. 2011; Wallach et al. 2015).

This paper presents a framework for evaluating anthropogenic impacts to ecological integrity and its effects on biodiversity in Mexico. The analysis of the relationship between ecological integrity and anthropogenic impacts is necessary to elucidate the thresholds at which ecological condition is able to sustain key ecological process, such as long-term predator-prey interactions. The goal is to establish a conceptual framework to associate measurable structural attributes, such as habitat loss and fragmentation, to biodiversity loss. With this spatial framework, several geo-indicators are derived (e.g., loss of ecosystem capacity to reorganize and sustain key ecological processes) such as anthropogenic impacts on predator-prey interactions can be observed.

\section{Ecological integrity and anthropogenic impacts}

Ecological integrity remains directly associated with ecosystem functioning by focusing on ecological processes. However, EI can be considered also a relative concept since a semantic definition of ecosystem functioning is not yet available (Jax 2010). Nonetheless, EI can be directly derived from ecological theory as a self-identity characteristic that emerges from the interaction of several components, or emergent properties (Jax 2010); i.e., a notion can be obtained from ecological concepts represented as latent variables, and observed or manifested variables that describe a specific ecological process (Mora 2017b). These components include concepts and measures of naturalness, stability, and self-organization in ecosystems (Odum 1988; Anderson 1991, 2012; Levin 2005; Winter et al. 2010); all of which are emergent properties that surface from structure, composition and function (Andreasen et al. 2001; Kandziora et al. 2013). However, the identification of key attributes for an ecological integrity evaluation requires the specification of spatially explicit assessments using quantitative spatial measures (Wurtzebach and Schultz 2016).

Using a particular functional property, ecological integrity can be inferred from an ecosystem's capacity to sustain ecological processes such as predator-prey systems. Due to habitat loss effects, changes in community assemblages and composition lead to a subsequent loss of species interactions, particularly disrupting functions at the top of ecological hierarchy (Valiente-Banuet et al. 2015). However, large carnivores as top predators are necessary for maintaining biodiversity and ecosystem function (Beschta and Ripple 2009; Miller et al. 2012; Ripple et al. 2014). Wide evidence exists that the occurrence of apex predators is associated with a high biodiversity value, providing a direct link between strategic conservation of flagship species and wider conservation goals (Sergio et al. 2006, 2008). Therefore, apex predators can be used as main receptors of anthropogenic impacts by analyzing modifications in their population viability, habitat functions, and species interactions. Predator-prey systems can also be used as significant receptors of anthropogenic impacts because these are the most visible elements of ecological integrity, i.e., they are associated with large animals, occupying high trophic levels, which have large spatial habitat requirements, and in turn are highly impacted by landscape transformation.

Self-organized and stable habitat systems are needed in order to sustain predator-prey interactions in natural landscapes. A natural condition is a concept that becomes directly related to anthropogenic impacts by measuring the resulting modifications in spatial habitat intactness as a form of habitat loss and fragmentation for apex predators and their prey. Concepts of stability and self-organization are directly related to the complexity in 
predator-prey interaction networks, and the role that apex predators play in maintaining landscape unity and coherence as mobile links (Lundberg and Moberg 2003). All these notions provide the elements for an EI operational definition by considering them as formative concepts or latent variables that describe an overall emergent property in ecosystems (for a deeper discussion on how these concepts are defined and measured, see Mora 2017b). In addition, EI is derived from observable attributes (or manifestations of emergent properties) that can be identified and represented as spatial information. As a change indicator, ecological integrity is also a measure of the effects that human activities have had on ecosystem properties and biodiversity, and can be a valuable tool to measure the anthropogenic impact of human activities.

As in many other parts of the world, long-term persistence and ecological viability of apex predators in Mexico are at peril due to ecological integrity loss. According to the most important conservation law for sustaining ecological balance in Mexico, i.e., Ley General de Equilibrio Ecológico y Protección al Ambiente, LGEEPA (Cámara de Diputados del H. Congreso de la Unión 2017), three Neotropical top predators, i.e., ocelots, margays, and jaguars (Leopardus pardalis, Leopardus wiedii, and Panthera onca), have been listed as endangered species (NOM-059-SEMARNAT 2010), and the jaguarondi (Puma yagouarondi) is categorized as threatened. On the other hand, only the black bear (Ursus americanus) is considered endangered as a Nearctic apex predator; while coyotes, pumas, and bobcats (Canis latrans, Puma concolor, and Lynx rufus) are not classified as threatened, and the Mexican wolf and brown bears (Canis lupus, and Ursus arctos) are considered extinct in the wild. However, the current extent of remnant habitat for all extant apex predators (both, Neotropical and Nearctic) is now less than $40 \%$ of their historical range. Furthermore, the remaining natural habitat for apex predators is characterized by very low ecological integrity conditions for all species.

As observed, the extent of habitat loss and ecological degradation threatens the long-term survival of apex predators in Mexico. The ecological habitat condition for Nearctic extant top predators such as cougars, coyotes, bobcats, and for the probably extinct Mexican wolf is highly degraded (Mora 2017a). Similarly, Neotropical top predators such as jaguars, jaguarondis, ocelots, and margays face large amounts of habitat transformation and loss as the major threat for long-term persistence. The loss of ecological integrity and degradation can be observed for all apex predators as a decrease in habitat quality and spatial restrictions for habitat use, which can be observed through several ecological indicators. These indicators describe the capacity of remnant landscapes to sustain ecological processes and functional roles associated with apex predators such as mobile trophic links, trophic connectivity, and habitat selection (Mora 2017a).

The ecological effects of losing ecosystem integrity have a strong influence on the ecological viability and long-term persistence of apex predators. The evolutionary capacity of predators is modified through human impacts by reducing the extent of the natural habitat that sustains viable populations. In addition, indirect impacts also disrupt animal mobility and their ecological roles as trophic links. It is imperative to analyze the magnitude of direct and indirect anthropogenic impacts associated with ecological degradation, particularly those related to the remnant habitat of top predators within their remaining distribution areas, in order to abate possible human-wildlife conflicts (such as livestock predation) and set conservation priorities, as natural landscape continues to be transformed. Understanding direct and indirect anthropogenic impacts is important for preventing species extinction and facilitating species recovery.

\section{Methods \\ A conceptual framework for evaluating anthropogenic impacts on ecological integrity}

The evaluation of impacts that modify the ecological integrity condition requires defining several components (Fig. 1). First, a proper identification of receptors is a key component for determining the significance of impact assessments. Instead of using isolated elements of biodiversity as receptors for an evaluation (e.g., species richness or particular species), the recognition of specific ecological processes as main receptors builds the link between human activities and the condition of ecosystems. Significance in impact assessments is then driven by the possible outcomes of modifying key ecological components related to structure, composition, and function within ecosystems, i.e., on ecological integrity. As a consequence, the result of modifying the natural condition of ecosystems by human activities is then manifested in the emergent (or latent) properties that stemmed from the process that sustain ecological integrity, i.e., stability, self-organization, and naturalness, which can be used as end-points for strategic environmental evaluations.

The spatial framework developed here is based upon the premise that human activities associated with landscape transformation are the major drivers of ecosystem change that have resulted in ecological integrity loss. A change that also has differential impacts on wildlife, particularly on apex predators. As ecological effects are identified, some outcomes of human activities (effects) can be observed directly, such as the loss of landscape integrity; defaunation, i.e., loss of predators and associated secondary extinctions; population isolation, i.e., the 


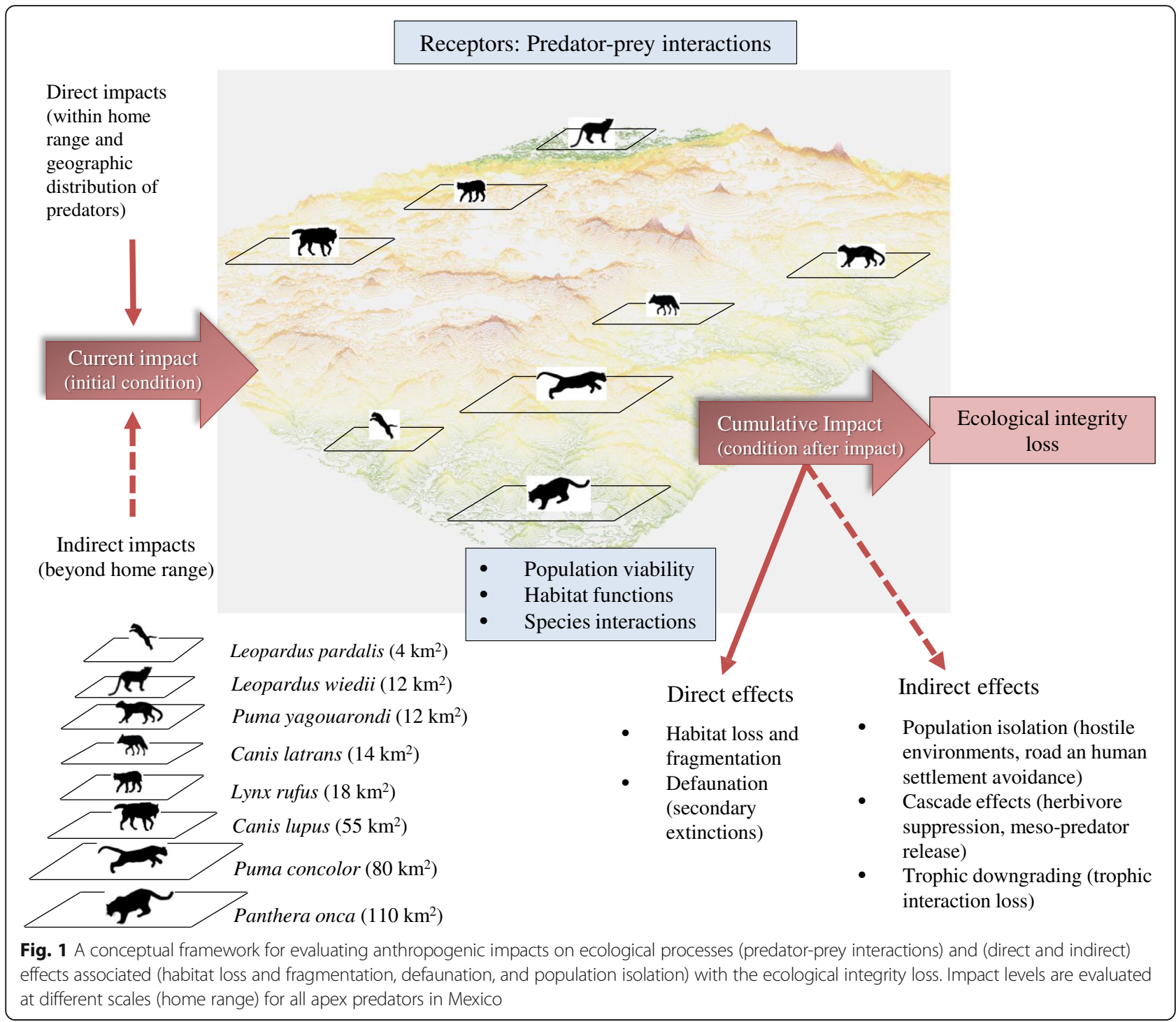

creation of inhospitable environments, road, and human settlement avoidance; and indirectly others, such as cascade effects, e.g., herbivore suppression and trophic downgrading.

Furthermore, these indicators are useful as mapping tools when they have a spatial representation in a geographic information system (GIS) tool (Atkinson and Canter 2011; Canter and Atkinson 2011). From the framework presented here, the information needed for a spatial decision-support system is directly translated into a GIS. First, human activities are expressed in a spatial form as observable impacts in the landscape. Direct impacts include landscape transformation (extent and variety), and the degree of human activity, which is a spatial set of observable impacts recorded within the home range of key species. Direct impacts also have differential effects on predators and prey, depending upon their spatial habitat requirements. As indirect impacts, human activities not only modify the natural condition for population viability but also degrade the current habitat by introducing inhospitable environments to species, e.g., roads, human settlements, and cultivated lands. Also, several forms of impacts with indirect effects can be described spatially by analyzing the barrier effects of human settlements- and road-related impacts on animal populations (Benítez-López et al. 2010; D’Amico et al. 2016). Both direct and indirect impacts provide a set of information within a GIS when they are integrated as spatial information.

Anthropogenic impacts, ecological integrity, and degradation characterization within historical distribution areas for apex predators

The landscape embodying all distribution areas for apex predators was characterized using ecological integrity information, as well as the impact level identified with the 
anthropogenic spatial indicators. The potential distribution of each top predator was obtained from species distribution models (SDMs) using an ecological niche modeling approach for all species. Here, all SDMs are gathered sources of information that were produced by different experts using the Genetic Algorithm for Rule Set Production (or GARP modeling system) based on climate data, and validated or revised with expert knowledge (Stockwell and Peters 1999). All SDMs are available in CONABIO's geolibrary of biodiversity information (SNIB-CONABIO; http://www.conabio.gob.mx/informacion/gis/). For all impact categories (or impact regions), the correspondent values of ecological integrity and ecological degradation were obtained in order to establish the relationship between ecological integrity, ecological degradation, and anthropogenic impact.

A statistical analysis for testing significant differences in ecological integrity and ecological degradation indicators, as well as the impact levels among groups of apex predator species, was performed using a simple $t$ test. Differences among groups of species were tested using patterns of geographic distribution (Neotropical vs. Nearctic), and risk categories (threatened, endangered, and non-listed). The goal was to identify if ecological integrity and impact indicators supported the threat categorization used in Mexico (NOM-059-SEMARNAT-2010), based upon group statistics and differences due to remnant natural habitat extent and impact level in transformed landscapes for all apex predators. The hypothesis tested establishes that group differences in ecological integrity and anthropogenic impacts should hold for different threat categories due to different patterns of impact extent within individual range and the two geographic patterns of distribution.

\section{Spatial indicators of ecological integrity}

Data for ecological integrity (EI) and ecological degradation (ED) consisted of previously obtained geographical sources of information, which are integrated as spatial hierarchical measures, and can be used as surrogates for evaluating ecosystem condition at different levels of ecological complexity (Fig. 2). This set of ecological indicators embodies an ecological integrity hierarchical framework (EIHF) (Mora 2017a). Here, the EIHF integrates the relevant ecological indicators that support the information contained at each hierarchical level. High order indicators of ecological integrity are used to evaluate the remnant natural habitat of apex predators after human transformation. The different levels in the hierarchy show relevant ecological information that includes basic or manifested information, continuing to subsequent higher levels (first-, second-, and third-order latent indicators) that support an ecological evaluation. At the top of the EIHF hierarchy, an overall ecological integrity measure indicates the general state of the ecosystems, which evaluates the condition resulting from landscape transformation, and is summarized from six manifest (observable) and six latent (emergent) attributes of ecosystem functioning and structure (Mora 2017b).

The use of latent variables allows an ecosystem condition analysis that can be disaggregated into three forms of ecosystem properties, i.e., self-organization, stability, and naturalness. Thus, by losing some of the emergent properties in ecosystems, the interaction among the properties at the second level of the EIHF defines the magnitude in which ecosystems have been degraded (while not completely losing all ecological properties) by human transformation. The third hierarchy level of ecological integrity includes functional (naturalness, stability, self-organization, mobile links, and ecological specialization), compositional (prey diversity, predator diversity, and functional diversity), and structural elements (habitat selection, remnant habitat, and habitat connectivity) all of which, when combined, defined the condition of integrity in ecological systems. This tri-dimensional representation of the ecological integrity concept is similar to the triangular representation of hierarchy in ecosystems (Dale and Beyeler 2001). Therefore, the EIHF provides an integrative view of all relevant elements that contribute to sustain landscape integrity for predator-prey interactions, covering key elements and offering an overall measure of status or condition that can be monitored by observable manifestations of ecological integrity.

\section{Development of spatial indicators of anthropogenic impacts}

Anthropogenic impact indicators were obtained from geographical sources of information that spatially characterize the impact level in the landscape (Table 1). Impact indicators are spatial attributes that are directly linked to habitat selection and use by apex predators. When they are analyzed at the home range level, it is possible to determine which habitats have the greatest impact according to the spatial habitat requirements of top predators. The ecology and spatial requirements for large carnivores, particularly top predators, suggest that recovery and persistence of viable populations will likely occur in larger patches of protected habitat, i.e., in a mosaic of patches with an impact gradient of human activity, that may show a collection of human-altered habitats. Therefore, in a highly human-modified environment, simply avoiding human-associated landscapes may not be feasible for most apex predators, as available, naturally occurring habitats become limited. Thus, apex predators may be forced to utilize human-transformed landscapes while avoiding negative interactions with humans (Dellinger et al. 2013). Therefore, the impact 


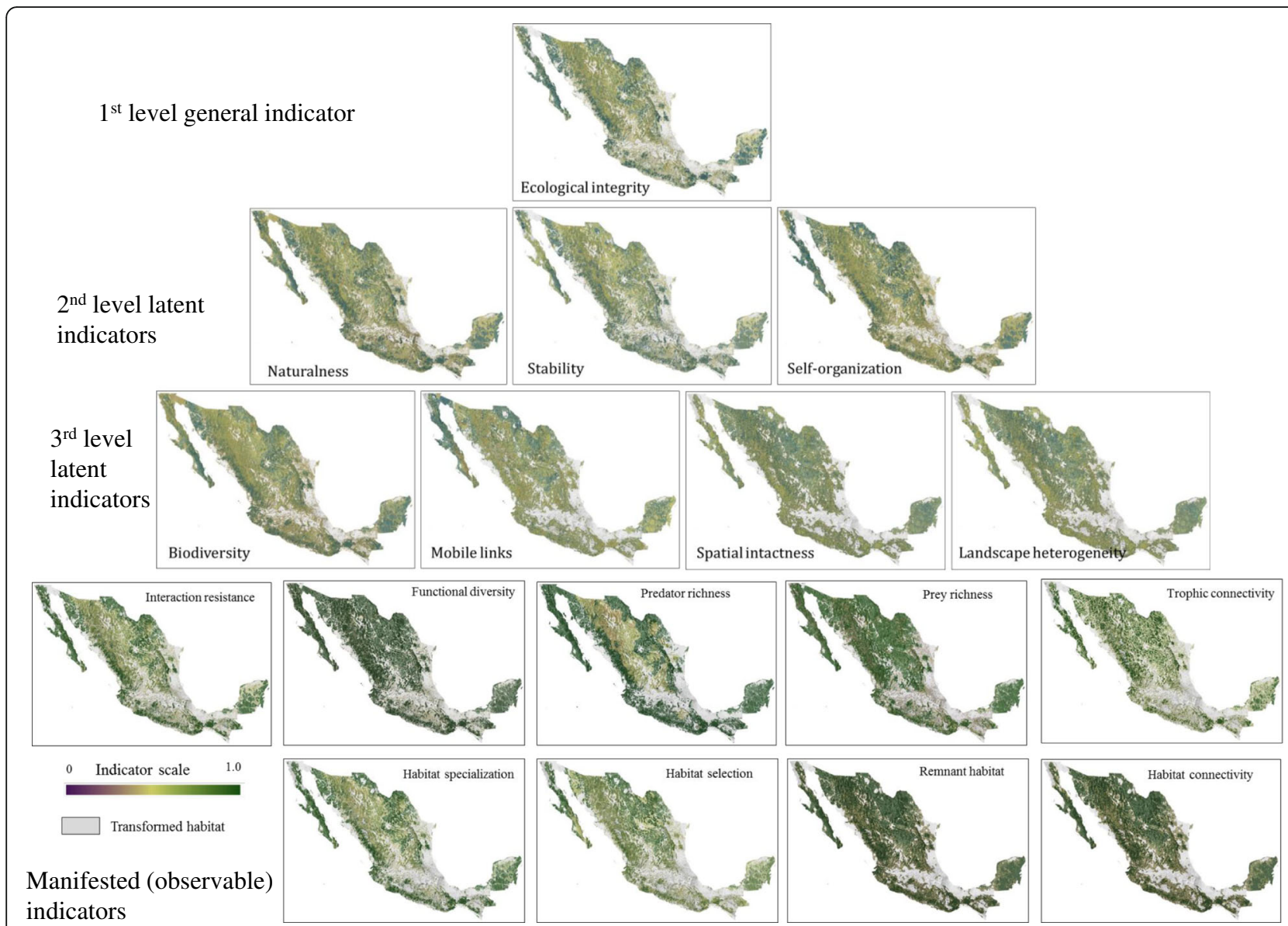

Fig. 2 The ecological indicator hierarchy network (EIHN) for evaluating the status of remnant landscapes for apex predators and their habitat

evaluation assessment should be restricted not only to natural but also impacted areas.

All derived sources of information that define impact levels, i.e., spatial impact indicators, were obtained with spatial analysis routines in Arc/Info GRID, which use the home range of all apex predator species as a focal analysis (for home range values indicated in Fig. 1), and expressed as spatial raster layers within a GIS, at $1 \mathrm{~km}^{2}$ resolution for all landscapes across Mexico. Primary data sources included (a) the amount of transformed landscape (all forms of agriculture and rangelands), (b) human settlement locations (towns and cities), (c) the location of highways and roads, and (d) human activity, which was indirectly obtained by remotely sensed observations of cities and population settlements. The several spatial sources used to estimate the amount of transformed landscape were derived from the land use-land cover (LULC) vegetation maps of Mexico, which identify the amount and spatial distribution of urban settlements, agriculture, aquaculture, forestry plantations, and cultivated grassland (INEGI series 4.0, circa 2010). The location of human settlements was obtained from INEGI's digital source (INEGI series 4.0, circa 2010). Sources of road and highways were obtained from Mexico's Institute of Transport (Instituto Mexicano del Transporte-IMT) road maps. Additionally, human activity was derived for this analysis from the 2010 Defense Meteorological Satellite Program/Operational Linescan System (DMSP/OLS) night-light observations that are indirectly related to human activity. The National Oceanic Atmospheric Administration-National Geophysical Data Center (NOAA-NGDC) has developed yearly composites of DMSP/OLS datasets captured in cloudless nights under very low or no lunar illuminance, which removes ephemeral events, leaving light signals from urban areas only. Therefore, DMSP/OLS observations show human-transformed landscapes with high human activity recorded by night-time satellite imagery. The digital datasets have a 6-bit radiometric resolution (1992 onwards), and are available at $1 \mathrm{~km}$ spatial resolution from the NOAA-NGDC website.

\section{A spatial classification of anthropogenic impacts using multivariate data analysis}

A multivariate classification of spatial impacts in the landscape was performed in order to define a baseline 
Table 1 Spatial impact indicators calculated to evaluate anthropogenic impacts in Mexico

\begin{tabular}{|c|c|c|c|}
\hline Indicator & Formulation & Definition and interpretation & References \\
\hline Land transformation & $\begin{array}{l}\text { Maximum value of a focal function of the } \\
\text { amount of transformed landscape (e.g., } \\
\text { cropland, rangeland, urban, agricultural } \\
\text { irrigation) }\end{array}$ & $\begin{array}{l}\text { The amount of habitat loss and fragmentation } \\
\text { within distribution areas of apex predators that } \\
\text { is primarily driven by land use change }\end{array}$ & $\begin{array}{l}\text { Adapted from Riitters } \\
\text { et al. (2002) }\end{array}$ \\
\hline Inhospitable environment & $\begin{array}{l}\text { Variety value of a focal function of the } \\
\text { different types of the transformed } \\
\text { landscape (e.g., cropland, rangeland, } \\
\text { urban, irrigated agriculture) }\end{array}$ & $\begin{array}{l}\text { The variety (e.g., the different land cover types) } \\
\text { of the landscape transformation can be also } \\
\text { expressed as the number of inhospitable } \\
\text { environments that a top predator may encounter } \\
\text { within its home range }\end{array}$ & $\begin{array}{l}\text { Adapted from Geneletti } \\
\text { (2004) }\end{array}$ \\
\hline Human activity & 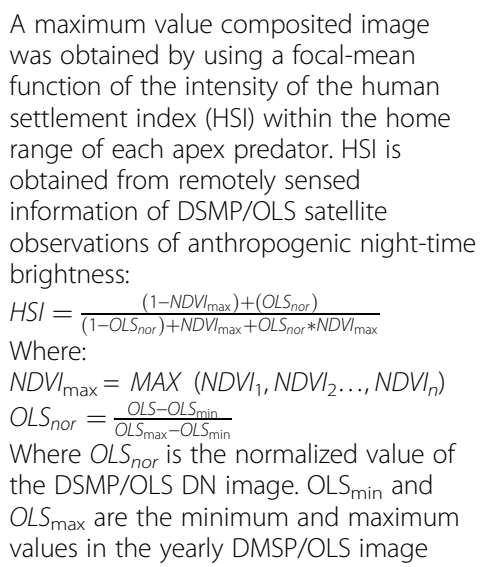 & $\begin{array}{l}\text { Remotely sensed estimates of human activity } \\
\text { using the DMSP/OLS satellite observations of } \\
\text { anthropogenic night-time brightness. Night-time } \\
\text { data provides quantitative data monitoring changes } \\
\text { in demographics, economy, energy composition, } \\
\text { and urban extent. Urban expansion has been } \\
\text { achieved by using a combination of normalized } \\
\text { difference of vegetation index (NDVI) from optical } \\
\text { sensors (MODIS) and DMSP/OLS night-time lights. } \\
\text { The HS indicate areas with human activity in a } 0 \\
\text { to } 1 \text { range of values. } \\
\text { A composite pixel-by-pixel maximum value of } \\
\text { the focal-mean maps represents collectively the } \\
\text { maximum impact of human activity within the } \\
\text { spatial home range of the apex predators }\end{array}$ & $\begin{array}{l}\text { Adapted from Ma et al. } \\
(2012,2015) ; \text { Huang } \\
\text { et al. (2016) }\end{array}$ \\
\hline $\begin{array}{l}\text { Human settlement } \\
\text { avoidance }\end{array}$ & $\begin{array}{l}\text { The avoidance of human settlements } \\
\text { was calculated as a function of the } \\
\text { point density within the apex predators' } \\
\text { home range (the greater density of } \\
\text { human localities within a home range, } \\
\text { the greater avoidance) }\end{array}$ & $\begin{array}{l}\text { Here, avoidance is as a density function of } \\
\text { point features in the landscape, which } \\
\text { represents human settlements (points). Then, } \\
\text { avoidance is an inverse function of the distance } \\
\text { to the major source or barrier, i.e., the greater } \\
\text { the distance to the barrier, the lesser avoidance } \\
\text { (or higher mobility) }\end{array}$ & $\begin{array}{l}\text { Adapted from Geneletti } \\
(2003,2004)\end{array}$ \\
\hline $\begin{array}{l}\text { Highway and road } \\
\text { avoidance }\end{array}$ & $\begin{array}{l}\text { Road and highway avoidance is as a } \\
\text { density function of linear features in } \\
\text { the landscape, which represents two } \\
\text { types of features, i.e., linear } \\
\text { infrastructure of highways and roads. } \\
\text { Road and highway avoidance were } \\
\text { obtained by calculating the Euclidean } \\
\text { distance from a source (e.g., road or } \\
\text { highway), and then filtered within the } \\
\text { home range of every apex predator }\end{array}$ & $\begin{array}{l}\text { Infrastructure avoidance results in the impairment } \\
\text { of animal movement patterns. The primary effect } \\
\text { of roads is road mortality, elevated predation and } \\
\text { human hunting. Road avoidance due to traffic } \\
\text { noise is another differential source of ecological } \\
\text { impacts, which differentiate the effects of highways } \\
\text { and rural roads, and it is probably more important } \\
\text { than road-kill }\end{array}$ & $\begin{array}{l}\text { Adapted from Geneletti } \\
(2003,2006) \\
\text { Forman and Alexander } \\
\text { (1998) } \\
\text { Laurance et al. (2009) } \\
\text { Zarco-González et al. } \\
\text { (2013) }\end{array}$ \\
\hline
\end{tabular}

for describing several levels of anthropogenic impact. While impact indicators are calculated as continuous variables, classification of continuous values into groups may present a better representation to facilitate the visualization of the resulting impact condition as categorical maps. In addition, qualitative representations of anthropogenic impact indicators allow the identification of meaningful condition states as well as permit the use of qualitative reasoning, especially when it is represented for data analysis and machine learning (Nuttle et al. 2009). Also, qualitative representations are particularly efficient when describing relationships among variables that are non-linear and complex (Uusitalo 2007), a feature that may be useful for establishing a non-linear relationship with ecological integrity loss. Discrete classes or intervals are easier to understand, use and explain, and are closer to knowledge-level representation (Liu et al. 2002).

However, data categorization is a non-trivial process. Although automatic data classification methods are available (Cao et al. 2014; Geaur Rahman and Zahidul Islam 2016; Nojavan et al. 2017), there is always a subjective component associated with the process of classification. Here, an unsupervised classification approach was selected to obtain different meaningful classes depicting accumulated impact. Then, a qualitative description of the accumulated impact was obtained by applying an unsupervised approach for deriving a classification scheme. Iterative self-organizing data 
(a) landscape transformation

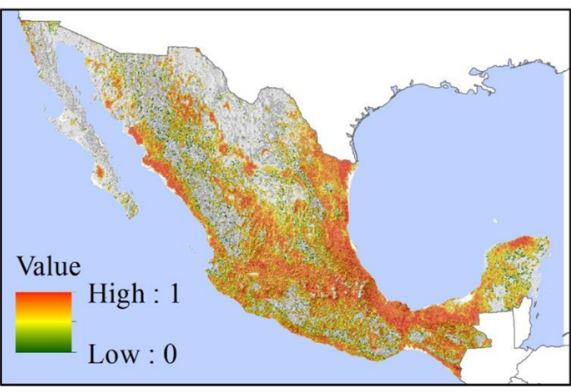

(c) human activity

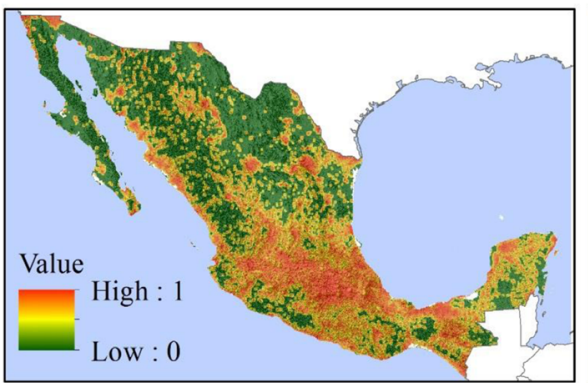

(e) road avoidance

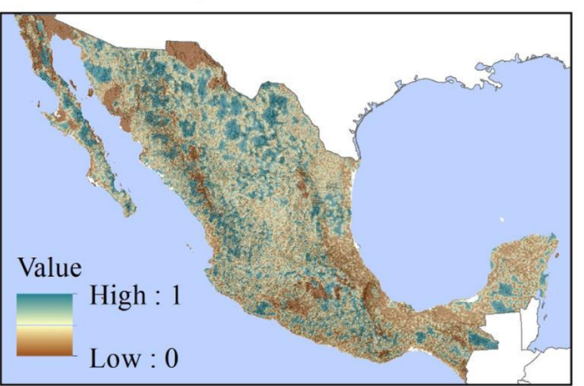

(b) inhospitable environments

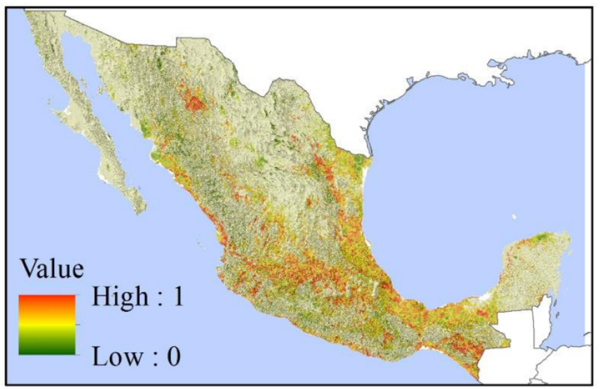

(d) human settlement avoidance

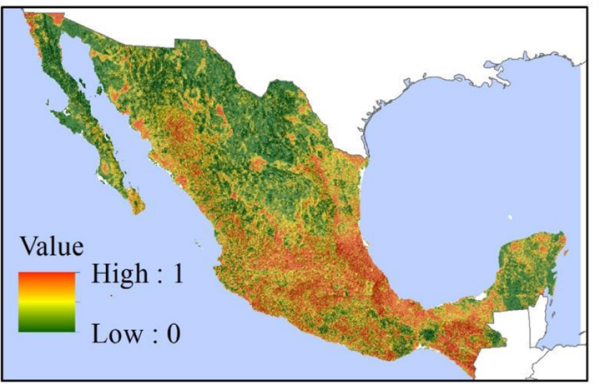

(f) highway avoidance

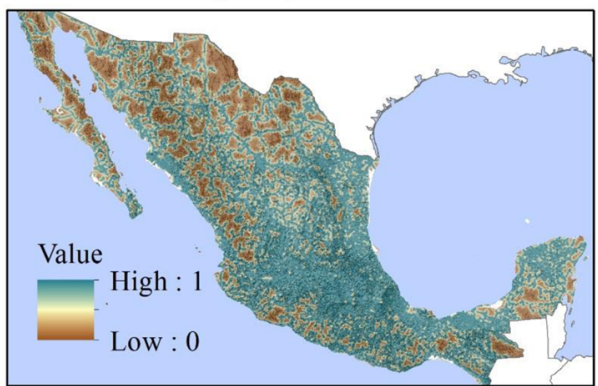

Kilometers

3,000

Fig. 3 Spatial indicators of anthropogenic impact. Direct effects are considered as a landscape transformation, $\mathbf{b}$ the number of inhospitable environments created by landscape transformation, and c human activity observed with DMSP-OLS night-time imagery. Indirect effects emerged from $\mathbf{d}$ human settlements avoidance, e road, and $\mathbf{f}$ highway avoidance. All indicators are obtained as focal functions of apex-predators home range (see text for explanation)

analysis (ISODATA) was used as the clustering algorithm (Ball and Hall 1965). The ISODATA classification algorithm is useful here because an unsupervised classification approach does not require previous knowledge, and it is helpful for exploring the data structure that represents significant different classes based upon spatial indicator characteristics. Later on, the classes obtained with the unsupervised approach were used to define different levels of impact, and each impact class was characterized with the mean values of each impact indicator and the ecological integrity indicator. Finally, the classified map of anthropogenic impacts was used to characterize the landscape of apex predators and their habitat.

\section{Results}

\section{Spatial indicators describing anthropogenic impacts}

The results obtained with the spatial analysis for obtaining quantitative impact measures are presented in Fig. 3. The transformed landscape affecting predator-prey interactions within the predator's home range was estimated for all top predators (Fig. 3a). In addition, the spatial representation of the number of inhospitable environments within home ranges for all apex predators was obtained (Fig. 3b). As observed, landscape transformation and the number of inhospitable environments are circumscribed within the distribution of the landscape transformed, so they represent a direct impact of human 
activities within the distribution areas of top predators. In addition, the impact of human activity, highways, roads, and human settlements, expressed as avoidance impact, was obtained for the entire landscape (Fig. 3c-f). These can be considered as indirect impacts because they were evaluated for the entire landscape and within home ranges of top predators, and are not restricted within distributional areas. Although direct and indirect impacts can be identified based on type and extent (i.e., within and beyond distributional areas and home ranges), no weights were assigned to place a differential contribution to the baseline map of accumulated impacts.

\section{A baseline map of anthropogenic impacts on predator-prey interactions}

The results obtained by applying the previous classification scheme showed the spatial distribution of the accumulated impacts in the landscape (Fig. 4). Six level-categories were identified from the classification, and later on described in the baseline map. These categories are (a) intact, with no apparent or minimal impact; (b) semi-intact; (c) concern, with relative levels of indirect impacts; (d) high anthropogenic impact; (e) severe anthropogenic impact; and (f) highly severe anthropogenic impact. The characterization obtained for each impact class show the contribution of individual impact indicators to the differences among impact classes (Fig. 5). As observed in Fig. 5, an intact landscape shows primarily the impacts of road and highway avoidance as indirect effects, without human activity or landscape transformation. Semi-intact environments are also characterized by the presence of human settlement avoidance, and on a lesser extent, human activity and landscape transformation. Landscapes with a status of concern showed an increase in landscape transformation (as compared with semi-intact landscapes) as well as the impact of inhospitable environments. The remaining three categories (high, severe, and highly severe) are characterized for increasingly different levels of landscape transformation and human activity.

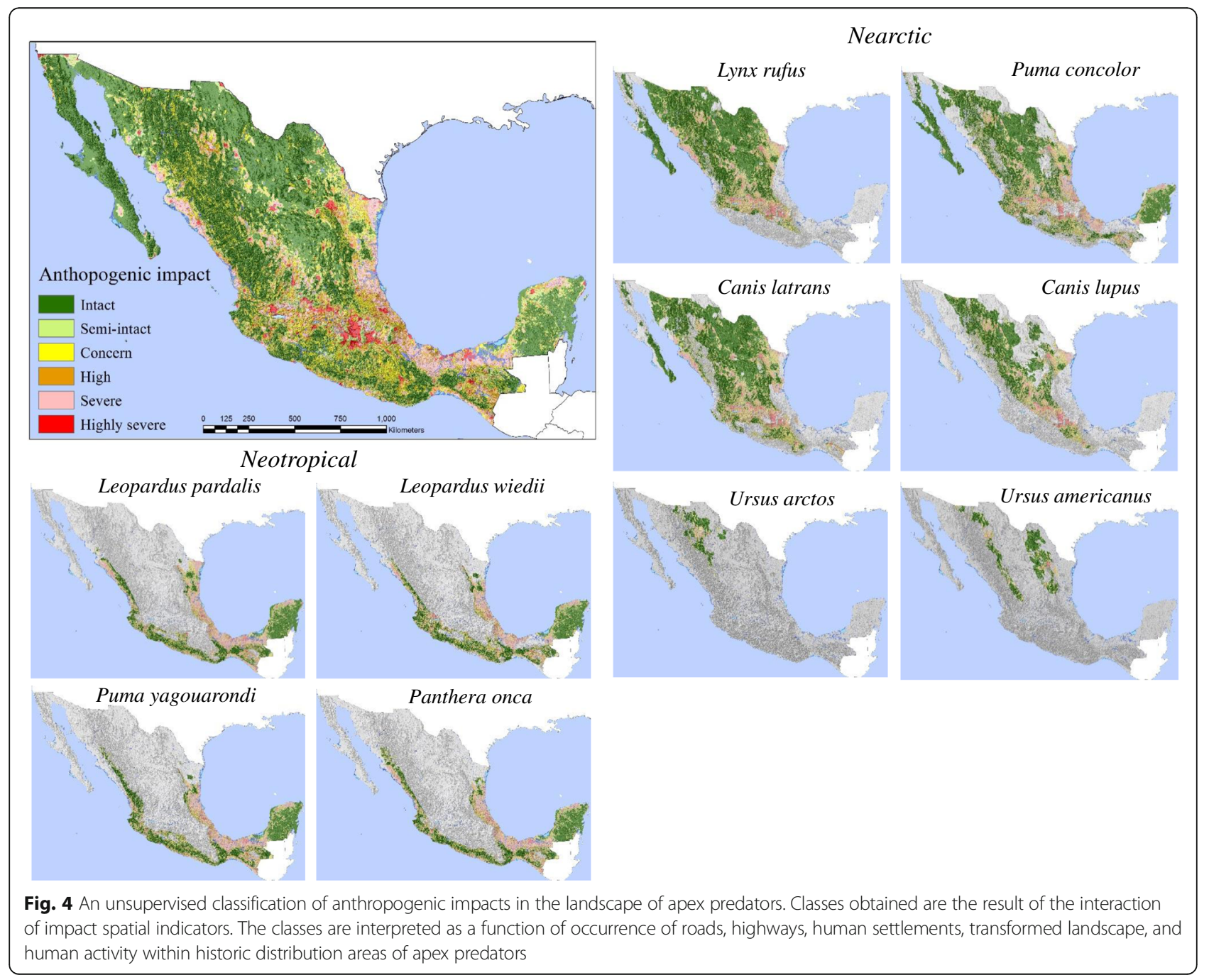




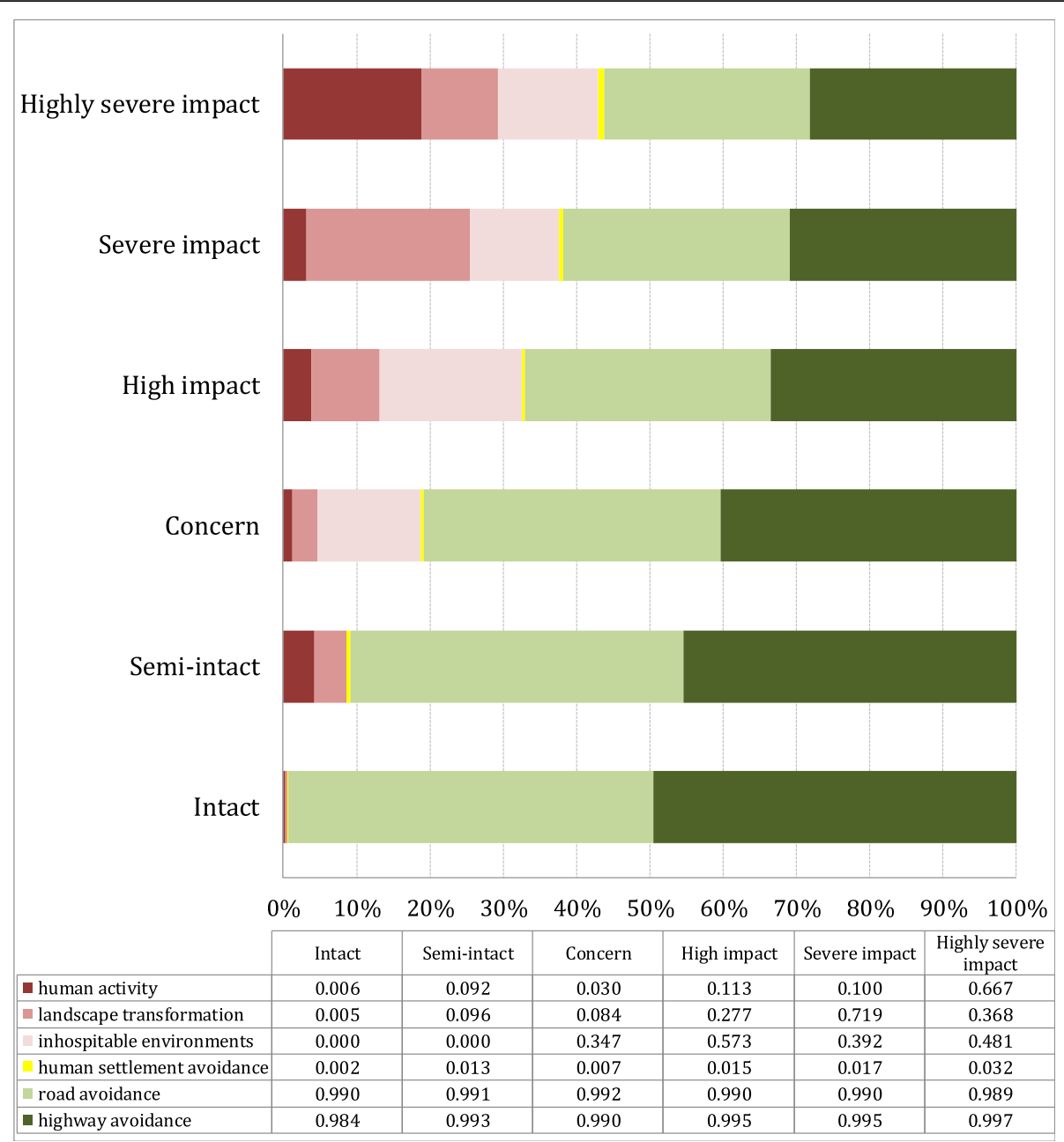

Fig. 5 The classification obtained according to the impact indicators values for the landscape of Mexico. Each class is interpreted as a function of cumulative factors of anthropogenic impact in the landscape affecting apex-predators' home range. Percentage values indicate the contribution of each anthropogenic impact indicator to the class category

\section{Anthropogenic impacts in the distribution range of apex predators}

The results obtained by characterizing the historical distribution areas with anthropogenic impact indicators for each apex predator are shown in Fig. 6. The spatial analysis characterizing their distribution range showed that Neotropical predators have significantly $(P<0.005)$ greater ecological integrity $\left(\mathrm{EI}_{\text {mean }}=0.21\right)$ and landscape transformation values $\left(\mathrm{LT}_{\text {mean }}=0.5\right)$ than Neartic predators $\left(\mathrm{EI}_{\text {mean }}=0.16 ; \mathrm{LT}_{\text {mean }}=0.35\right)$, respectively (Fig. 6a). On the other hand, Nearctic predators $\left(\mathrm{ED}_{\text {mean }}=0.49\right)$ have significantly greater ecological degradation $(P<$ $0.005)$ than their Neotropical counterparts $\left(E_{\text {mean }}=\right.$ 0.28). There are no significat differences in impact levels for apex predators based on their Nearctic or Neotropical patterns of distribution, indicating that anthropogenic impact is a generalized threath within the distribution areas for apex predators, regardless of their biogeographic distribution pattern. However, the amount of intact areas is slightly higher for Neartic than for Neotropical predators. In addition, no significant differences were found for all impact indicators, based upon threath categories. The relationship between those indicators that showed significant differences between patterns of biogeographic distribution, and landscape transformation is showed in Fig. 7.

\section{Ecological integrity and anthropogenic impacts in the landscape of apex predators}

There is an inverse direct relationship between anthropogenic impact and ecological integrity (EI) for all apex predators (Fig. 8). As expected, the ecological integrity decreases as impact becomes more severe in their distribution areas. The average values of ecological integrity for all impact classes showed a tipping point for the highest impact classes when EI reaches a 0.4 value or below. From 

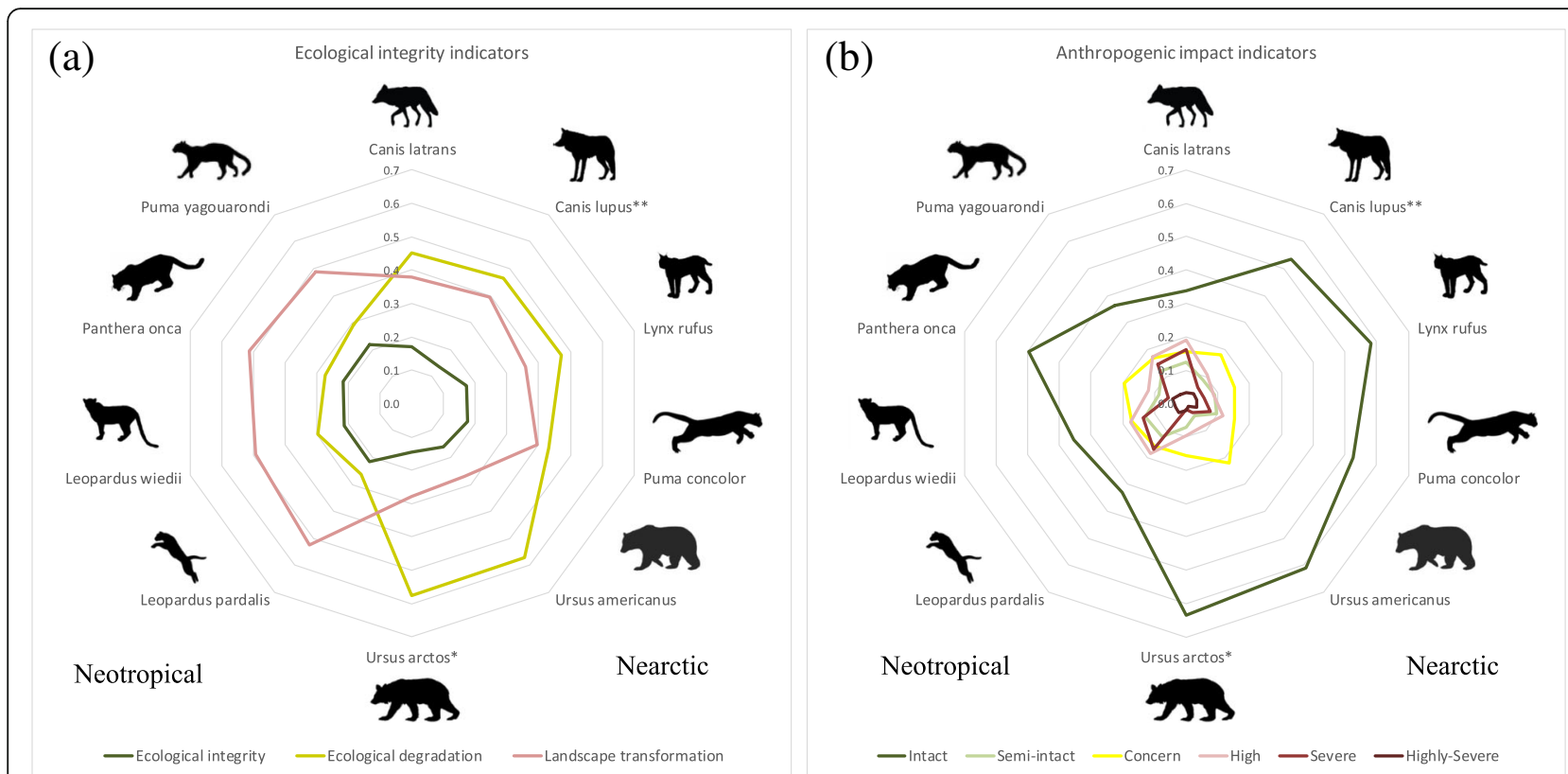

Fig. 6 Characterization of the historical distribution areas for all apex predators according to a the ecological integrity indicators, ecological degradation and landscape transformation, as well as $\mathbf{b}$ the impact baseline categories within distribution areas of apex-predators

that point, the accumulated impact in the landscape ranges from severe to highly severe. The main factor contributing to the impact severity is primarily associated with landscape transformation, and later on, with the amount of human activity (Fig. 5).

The ecological integrity values for all impact classes in the landscape of all apex predators showed a consistent pattern (Fig. 8). Areas identified as intact, where the most important impact geo-indicator in the landscape is road and highway avoidance, showed an average value of $\mathrm{EI}=0.75 \pm 0.003$ for Neotropical predators and $E I=0.70 \pm 0.018$ for Nearctic predators. Semi-intact areas show an ecological integrity value ranging from $\mathrm{EI}=0.53 \pm 0.002$ to $\mathrm{EI}=0.46 \pm 0.023$ for Neotropical and Nearctic predators, respectively. However, intact landscapes for Nearctic predators show a considerable amount of ecological degradation (Fig. 6a), particularly in spatial connectivity due to road and highway avoidance (Fig. 5). Very low values of ecological integrity are observed in high impact to highly severe impact classes (Fig. 8).

\section{Discussion}

Ecological integrity loss, as a way to analyze the scope and magnitude of anthropogenic impacts on key ecological processes, can be quantified using the spatial analysis framework presented here. This framework gives a spatial dimension to an anthropogenic impact assessment based upon ecological integrity loss. Thus, ecological integrity loss is observed as the reduction or degradation of ecosystem's capacity to sustain key ecological processes, i.e., predator-prey systems, by modifying the integrity in predator-prey interactions and intact habitat. As observed, human activities have a wide spatial dimension, which strongly affects the long-term persistence, ecological viability, and evolutionary capacity of apex predators. Anthropogenic impacts have direct and indirect effects that modify the geographic representation, ecosystem integrity, population viability, and extinction risk of apex predators, as key components of ecosystem stability, self-regulation, and habitat naturalness.

With the use of the anthropogenic indicators derived with the framework proposed here, a baseline for monitoring future impacts was successfully obtained. The framework also evaluates the cumulative effects, and helps to explore the ecological effects derived from ecological integrity loss. As observed, direct and indirect impacts have a generalized effect (over the wide variety of habitats and ecosystems in Mexico) on apex predators, reducing the ecological integrity of their remnant natural areas, and consequently resulting in ecological degradation. This situation is observed for all apex predators, regardless of their biogeographic patterns of distribution, and independently of their current risk status, which in turn may affect management decisions for their conservation.

\section{A baseline for anthropogenic impacts in the Mexican landscape}

The baseline of anthropogenic impacts as a categorical map shows the impact level on ecological processes that maintain ecosystem's capacity to sustain predator-prey interactions, as well as the viability of population and the integrity of their habitat. This baseline map is an integration of several impact indicators occurring at the 


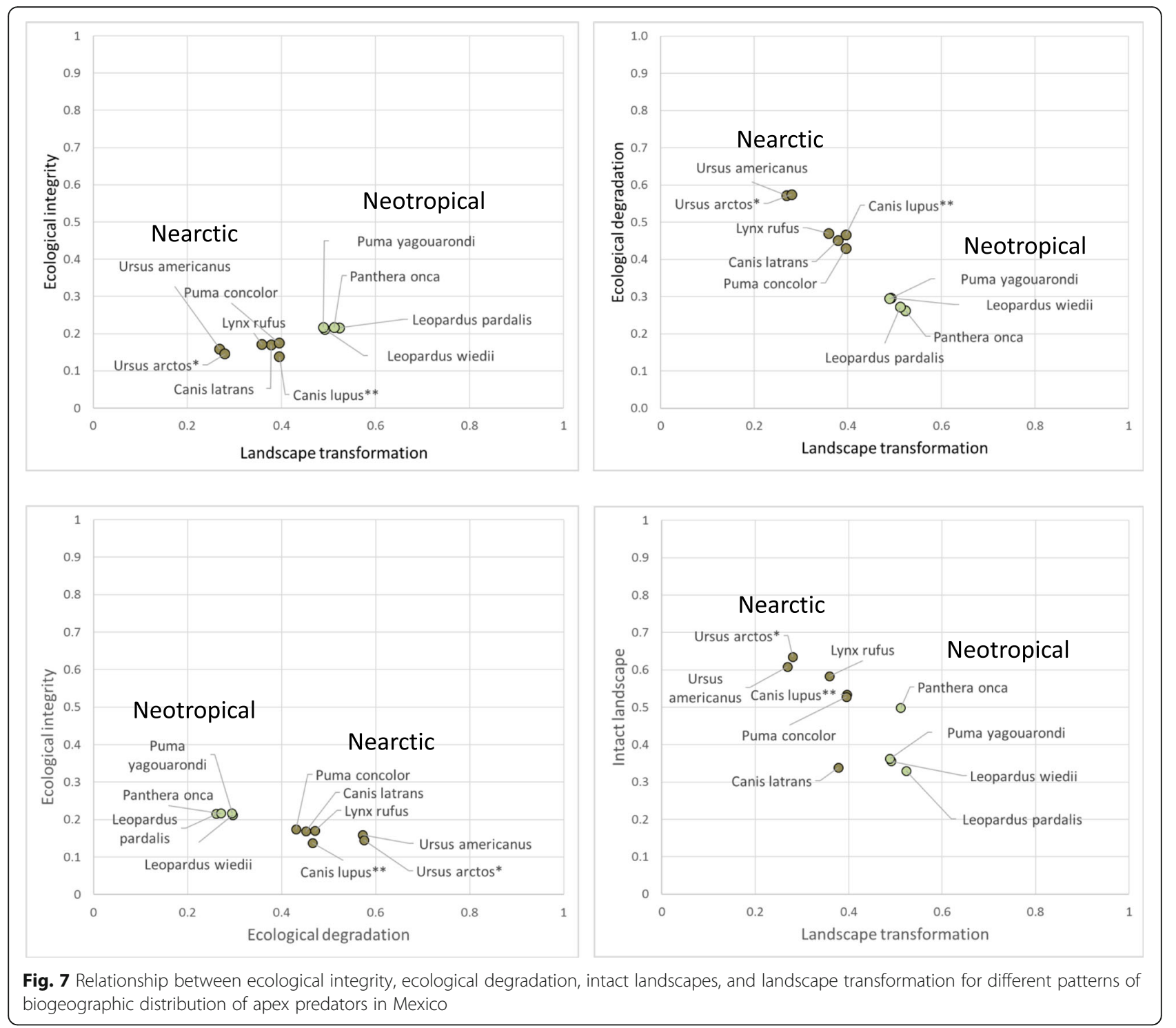

landscape level, which have a direct impact at the home range of apex predators. As starting point of an evaluation, this baseline also shows the potential accumulated impact of human activity on animal populations (particularly of top predators and their prey) and may help to elucidate several effects that include local reductions in population density, altered reproduction and mortality rates, and altered movement and dispersal patterns (barriers). In addition, it may also be used for evaluating the cumulated impacts in the landscape caused by linear infrastructure (roads and highways), human settlements, and landscape transformation. When no significant differences exist for all predators that are listed with different risk categories, there is the possibility that impact levels of a generalized anthropogenic impact have the same potential effects for all apex predator species. The impact level is high for all predators, and the resulting ecological integrity is very low.

As described, highway and road avoidance are prominent effects in all impact categories for top predators, which have a generalized impact in the landscape (Fig. 3e, f). Roads have differential effects on wildlife populations; directly by affecting the mortality of wildlife and as a significant demographic sink for some populations and species, as well as acting as physical barriers (Laurance et al. 2009). Then, roads limit the access of animals to vital resources, therefore decreasing the area of available habitat, and may potentially limit the movement and dispersal of individuals, fragmenting populations and consequently reducing gene flow (Holderegger and Di Giulio 2010).

In the baseline map obtained here, substantial fragmentation is observed for all habitats due primarily to road 

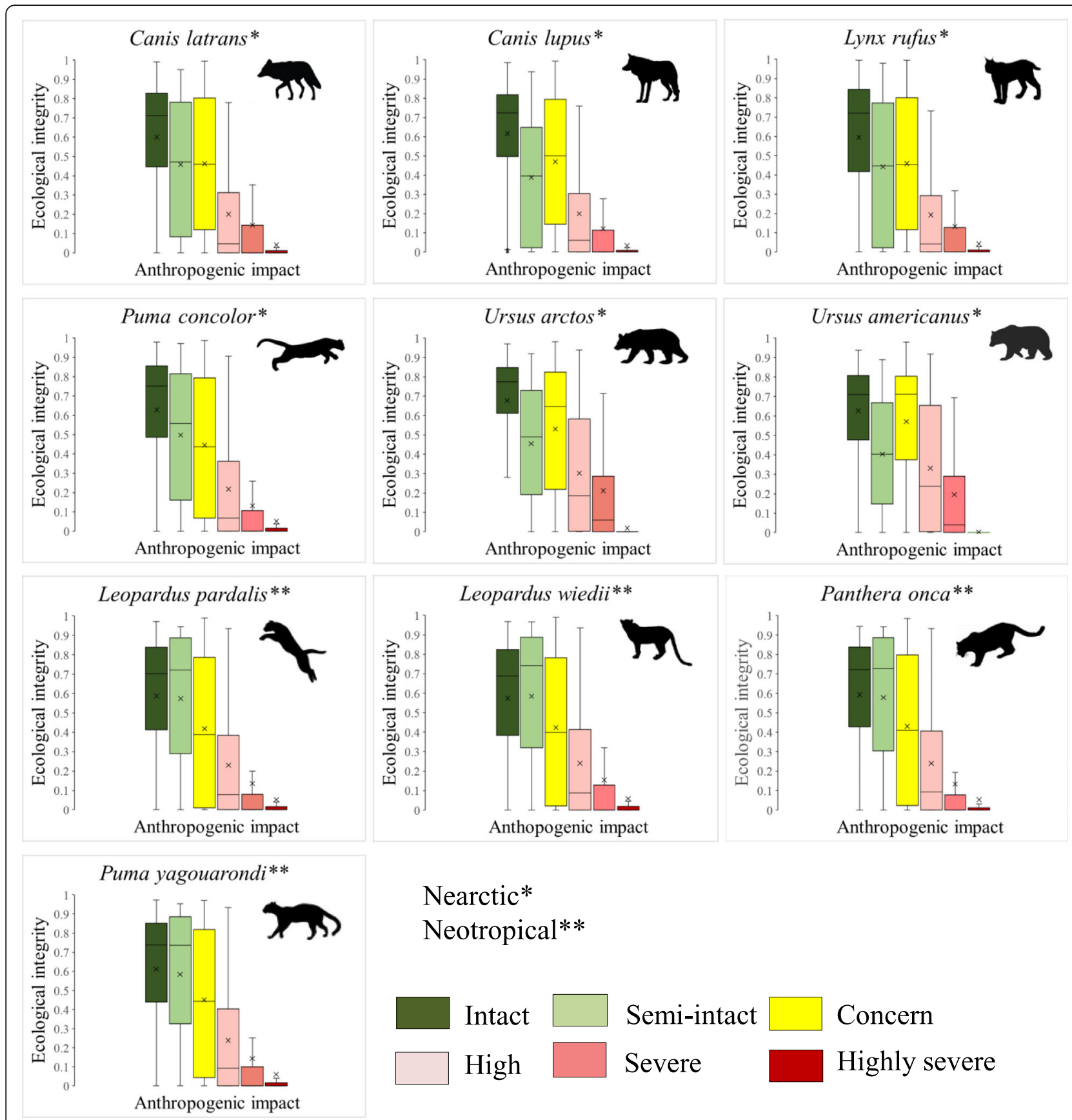

Fig. 8 Ecological integrity characterization for all Nearctic and Neotropical apex predators and all impact classes identified within their distributions areas in Mexico. As observed an inverse relationship between ecological integrity and anthropogenic impacts holds for all apex predators in their distribution areas

avoidance, although considerable isolation can also be observed for highway avoidance, except maybe for some nontransformed areas, particularly in the northern part of the country (Fig. 4). Although its influence is less, a generalized road avoidance effect may suggest a greater fragmentation effect due to roads, rather than highways, especially for Nearctic predators that show a social behavior in selecting habitats (as may occur for wolf packs). However, highway avoidance can have isolation effects also for large felines that show traffic avoidance, such as pumas. Furthermore, road density is likely to correlate with the overall intensity of land use. It may thus be difficult to distinguish the isolation effects of infrastructure from direct impacts related with urbanization, agriculture, recreation, 
hunting, or forestry. As the spatial indicators showed, indirect effects associated with road and highway avoidance go beyond the home range for all apex predators.

Direct effects, i.e., within apex predators' home range, are also observed in the baseline map due to natural land transformation and human occupation of the landscape. Human activity, the number of inhospitable environments, and land transformation are indicators that better characterize the high, severe, and highly severe impact classes identified for apex predators. Human activity, in addition to habitat fragmentation of accessible habitat, is also a main driving factor in suitable habitat loss and fragmentation. While transformed rural areas are not heavily populated, they do represent a loss of quality habitat for species, hindering their abilities to perform their ecological role in predation, this probably being more important in areas with high human activity. As observed with satellite night-time imagery, the human activity indicator is highly associated with large cities or heavily populated areas. These drastically altered landscapes are unlikely to support viable wildlife populations, particularly for large predators.

\section{Anthropogenic impacts in the ecological integrity landscape of top predators}

The results obtained showed that anthropogenic impacts have a generalized effect on all apex predators, regardless of their biogeographic pattern of distribution, and their conservation risk status (Table 2). Therefore, all apex predators should be included in the same conservation category (particularly those not listed such as pumas, coyotes, and bobcats) for the protection of their species interactions, their habitat, and at the end, the ecological integrity of the ecosystems in which they occur. Due to LULC dynamics in the country, Neotropical top predators tend to have higher proportions of transformed and human-dominated landscapes, which results in higher accumulated impacts, particularly for medium-size predators such as ocelots and margays, which have less intact landscapes than jaguars and jaguarondis. With the exception of coyotes, Nearctic top predators, particularly bears, showed less accumulated impacts. Nearctic felines (pumas and bobcats) have similar amount of accumulated impacts, as well as the landscape for the Mexican wolf, where more than $50 \%$ of their historical distribution can be classified as intact, but with a significant amount of road and highway

Table 2 Anthropogenic impact characterization according to the baseline map and the historical distribution areas of apex-predators. Values indicate the average value of ecological integrity indicators and the percentage of each impact class category within the distribution areas for all apex predators in Mexico ( ${ }^{*}$ significant at 0.001)

\begin{tabular}{|c|c|c|c|c|c|c|c|c|c|c|c|}
\hline & Distribution & NOM-059 & $\begin{array}{l}\text { Ecological } \\
\text { integrity }\end{array}$ & $\begin{array}{l}\text { Ecological } \\
\text { degradation }\end{array}$ & $\begin{array}{l}\text { Landscape } \\
\text { transformation }\end{array}$ & Intact & $\begin{array}{l}\text { Semi- } \\
\text { intact }\end{array}$ & Concern & $\begin{array}{l}\text { High } \\
\text { impact }\end{array}$ & $\begin{array}{l}\text { Severe } \\
\text { impact }\end{array}$ & $\begin{array}{l}\text { Highly severe } \\
\text { impact }\end{array}$ \\
\hline Leopardus pardalis & Neotropical & Endangered & 0.215 & 0.261 & 0.523 & $32.9 \%$ & $12.2 \%$ & $16.0 \%$ & $18.4 \%$ & $16.9 \%$ & $3.6 \%$ \\
\hline Leopardus wieddi & Neotropical & Endangered & 0.212 & 0.296 & 0.491 & $35.5 \%$ & $12.9 \%$ & $17.2 \%$ & $17.6 \%$ & $13.5 \%$ & $3.4 \%$ \\
\hline Puma yagouarondi & Neotropical & Threatened & 0.217 & 0.294 & 0.488 & $36.3 \%$ & $12.1 \%$ & $16.7 \%$ & $17.3 \%$ & $14.5 \%$ & $3.2 \%$ \\
\hline Panthera onca & Neotropical & Endangered & 0.216 & 0.272 & 0.512 & $49.8 \%$ & $8.6 \%$ & $19.5 \%$ & $12.1 \%$ & $5.8 \%$ & $4.3 \%$ \\
\hline Canis latrans & Nearctic & Non-listed & 0.170 & 0.452 & 0.378 & $33.9 \%$ & $12.4 \%$ & $15.4 \%$ & $18.9 \%$ & $16.1 \%$ & $3.2 \%$ \\
\hline Canis lupus & Nearctic & Extinct & 0.138 & 0.466 & 0.396 & $53.4 \%$ & $8.5 \%$ & $17.8 \%$ & $10.7 \%$ & $6.1 \%$ & $3.5 \%$ \\
\hline Puma concolor & Nearctic & Non-listed & 0.174 & 0.430 & 0.395 & $52.8 \%$ & $9.7 \%$ & $15.1 \%$ & $11.6 \%$ & $7.6 \%$ & $3.3 \%$ \\
\hline Lynx rufus & Nearctic & Non-listed & 0.171 & 0.470 & 0.358 & $58.3 \%$ & $8.9 \%$ & $15.1 \%$ & $8.7 \%$ & $5.7 \%$ & $3.3 \%$ \\
\hline Ursus americanus & Nearctic & Endangered & 0.159 & 0.572 & 0.269 & $60.9 \%$ & $4.5 \%$ & $22.1 \%$ & $8.3 \%$ & $3.3 \%$ & $0.9 \%$ \\
\hline Ursus arctos & Nearctic & Extinct & 0.145 & 0.575 & 0.280 & $63.4 \%$ & $7.3 \%$ & $15.8 \%$ & $9.5 \%$ & $1.9 \%$ & $2.1 \%$ \\
\hline All Non-listed & & & 0.172 & 0.378 & 0.451 & 0.483 & 0.103 & 0.152 & 0.131 & 0.098 & 0.033 \\
\hline All Extinct & & & 0.142 & 0.338 & 0.520 & 0.584 & 0.078 & 0.168 & 0.101 & 0.040 & 0.028 \\
\hline$P(T \leq t)$ & & & 0.0400 & 0.3117 & 0.214 & 0.1701 & 0.0710 & 0.1847 & 0.2195 & 0.1122 & 0.3127 \\
\hline All Non-listed & & & 0.172 & 0.377 & 0.172 & 0.483 & 0.103 & 0.152 & 0.131 & 0.098 & 0.033 \\
\hline All Endangered & & & 0.201 & 0.449 & 0.350 & 0.448 & 0.095 & 0.187 & 0.141 & 0.098 & 0.030 \\
\hline $\mathrm{P}(\mathrm{T} \leq t)$ & & & 0.0665 & 0.1639 & 0.0479 & 0.3671 & 0.3668 & 0.0411 & 0.4014 & 0.4974 & 0.4006 \\
\hline $\begin{array}{l}\text { All Neotropical } \\
\text { predators }\end{array}$ & & & 0.215 & 0.281 & 0.504 & $38.6 \%$ & $11.4 \%$ & $17.3 \%$ & $16.3 \%$ & $12.7 \%$ & $3.6 \%$ \\
\hline $\begin{array}{l}\text { All Nearctic } \\
\text { predators }\end{array}$ & & & 0.159 & 0.494 & 0.346 & $53.8 \%$ & $8.5 \%$ & $16.9 \%$ & $11.3 \%$ & $6.8 \%$ & $2.7 \%$ \\
\hline$P(T \leq t)$ & & & $0.0001^{*}$ & $0.0004^{*}$ & $0.0001^{*}$ & 0.0150 & 0.0403 & 0.3747 & 0.0238 & 0.0528 & 0.0501 \\
\hline
\end{tabular}


avoidance. This may have barrier effects in remnant populations or re-introduction programs, especially by affecting habitat selection and by restricting movement. In addition, roads may have genetic effects in intact and semi-intact areas by decreasing diversity and increasing genetic differentiation or distance between populations or individuals (Holderegger and Di Giulio 2010). Additional effects may include affecting felid marking behavior (particularly in territorial solitary felids, such as pumas and bobcats) since human objects in the environment stand out in natural habitats and serve as scent marking for territorial purposes (Krofel et al. 2017).

The anthropogenic impact of concern is the second category of importance indicating anthropogenic impact in the landscape. Here, indirect effects are meddling with other forms of impact. The presence of inhospitable environments due to landscape transformation becomes an important source of accumulated impact, probably producing several direct and indirect effects, particularly for Nearctic predators as bears. In contrast, areas showing high to highly severe impacts are greater for Neotropical felines. Human population density and habitat alterations may exert strong negative effects on Neotropical felines (like jaguars), particularly when the impact interacts with ecosystem productivity (Jędrzejewski et al. 2017). For several Nearctic predators such as black bears and the Mexican wolf, areas of concern showed higher average EI values than those observed in semi-intact areas. This may have important implications for restoration efforts, or management activities directed to re-introduce important species, particularly in areas with high levels of human activity.

The relationship between ecological integrity loss and the level of anthropogenic impact is clear for all apex predators. As several impacts accumulate in the landscape, the less ecological integrity is observed in remaining areas. A critical point was identified for defining an ecological threshold, where ecosystem properties can be severely impacted due to human activities, and where the landscape that sustains ecological suitable habitat and population viability is drastically threatened (Fig. 8). In all cases, the ecological integrity loss is consistently around $\mathrm{EI}=0.4$ for all apex predators, and defines the threshold when anthropogenic impacts become high. When this tipping point is reached, the anthropogenic impact becomes high to highly severe. Noticeably, EI values ranged considerably for intact and semi-intact areas, indicating a possible level of ecological degradation for the remaining habitat of apex predators. Nevertheless, the definition of an ecological integrity threshold for anthropogenic impact may be used for consistent evaluations of environmental impact assessments, and to guide decision making for avoiding unwanted accumulated impacts.

\section{Implications for management and assessments}

To date, the environmental impact assessment (EIA) of human activities in the Mexican landscape had not included a specific framework to link key ecological processes (such as predator-prey interactions) as receptors of environmental modifications. The status of predator-prey interactions and their habitat seemed to be suitable to enable EIA based on ecological integrity. Although ecosystem and habitat suitability approaches may reveal limitations for the EIA process (Gontier et al. 2006), by using ecological integrity measures within an impact assessment, then multiple scales and biodiversity levels are considered, and ensure adequate consideration of potentially serious and synergistic ecological effects (Treweek 1996; Brownlie et al. 2013).

The framework presented here can help to establish the current (baseline) conditions for evaluating the effects derived from future impacts associated with human landscape transformation in the integrity of ecosystems for Mexico. The analysis of baseline conditions highlighted the relevance of indirect effects as road and highway avoidance (e.g., habitat fragmentation), as well as important as direct effects (e.g., habitat loss) for implementing environmental impact assessments. These baseline conditions can be also useful for implementing strategic environmental assessments (Karlson et al. 2014) by including cumulative impacts for directing spatial decision making. Strategic evaluations can use ecological integrity attributes as directed ending points for ecological impact assessments, particularly when restoration efforts are derived from impact evaluations (Ritchie et al. 2012). Since animal movement is essential for ecosystem functioning and food web dynamics (particularly predator-prey interactions), it is imperative to include the effects of reducing animal mobility from landscape transformation. Animal movement can have a critical role in human-wildlife coexistence (de Souza et al. 2018), but the necessary space for wildlife to roam freely is an undeniable factor to consider in management and conservation plans.

\section{Conclusions}

A spatial indicator framework using ecological integrity loss as the main factor for maintaining predator-prey interactions defined the significance of anthropogenic impact assessments in Mexico. The accumulated impacts in the landscape showed mostly great indirect effects, which may result in population isolation due to road, highway, and settlement avoidance. This prominent impact of human activity reduces the mobility of apex predators in the landscape. The resulting effects of restricting animal movements can have significant consequences in ecosystem properties regardless of the underlying mechanism (e.g., road, highway, or human settlements avoidance), by interrupting their functional 
role as mobile links and food-wed dynamics, especially for top predators. In addition, landscape transformation has resulted in an increase of inhospitable environments and habitat loss and fragmentation for all apex predators. Negative impacts are complemented by human activity in densely populated areas. The level and intensity of anthropogenic impacts has resulted in the loss of ecological integrity, especially when a critical point is reached and the impact level is classified as high. The integration of spatial indicators as a way to evaluate anthropogenic impacts on the landscape can serve as a baseline for future ecological environmental impact assessments.

\begin{abstract}
Abbreviations
CONABIO: Comisión Nacional para el Uso y la Conservación de la Biodiversidad; DMSP: Defense Meteorological Satellite Program; El: Ecological integrity; EIA: Environmental impact assessments; GIS: Geographic information systems; ISODATA: Iterative self-organizing data analysis; LGEEPA: Ley General del Equilibrio Ecológico y la Protección al Ambiente; LULC: Land use and land cover; NOAA-NGDC: National Oceanic Atmospheric Administration-National Geophysical Data Center; NOM-059: Norma Oficial Mexicana-059; OLS: Operational linescan system; SDMs: Species distribution models; SEA: Strategic environmental assessment; SNIB: Sistema Nacional de Información sobre la Biodiversidad
\end{abstract}

\section{Acknowledgements}

I would like to thank Dr. Rodolfo Dirzo, Dr. Esther Quintero (CONABIO), and M.S. Rafael Ramirez for insightful comments on previous manuscripts, and three anonymous reviewers that help to provide a better context for this paper. Also I would like to thank Janet Lauderd for a language review. This research was supported by CONABIO and is part of the Spatial Decision Support System for evaluating human impacts on biodiversity (SIESDIB).

\section{Funding}

This study was funded by Comisión Nacional para la Conservación y Uso de la Biodiversidad, México, as a part of its yearly operational program.

\section{Availability of data and materials}

Not applicable.

\section{Authors' contributions}

FM carried out all analysis and wrote the paper. The author read and approved the final manuscript.

Ethics approval and consent to participate

Not applicable.

\section{Consent for publication}

Not applicable.

\section{Competing interests}

The author declares that he has no competing interests.

\section{Publisher's Note}

Springer Nature remains neutral with regard to jurisdictional claims in published maps and institutional affiliations.

Received: 10 July 2018 Accepted: 17 October 2018

Published online: 06 November 2018

\section{References}

Anderson JE (1991) A conceptual framework for evaluating and quantifying naturalness. Conserv Biol 5:347-352.

Anderson P (2012) Complexity theory and organization science. Organ Sci 10: 216-232.

Andreasen JK, Neill RVO, Noss R, Slosser NC (2001) Considerations for the development of a terrestrial index of ecological integrity. Ecol Indic 1:21-35.
Angermeier PL, Karr JR (1994) Biological integrity versus biological diversity as policy directives. Bioscience 44:690-697. https://doi.org/10.2307/1312512.

Atkinson SF, Canter LW (2011) Assessing the cumulative effects of projects using geographic information systems. Environ Impact Assess Rev 31:457-464. https://doi.org/10.1016/j.eiar.2011.01.008.

Ball G., Hall DJ (1965) ISODATA, a novel method of data analysis and pattern classification. Technical Report.Information Science Branch, Office of Naval Research SRI Project 5533 Standford Research Institute, Menlo Park, California, $61 \mathrm{pp}$.

Benítez-López A, Alkemade R, Verweij PA (2010) The impacts of roads and other infrastructure on mammal and bird populations: a meta-analysis. Biol Conserv 143:1307-1316. https://doi.org/10.1016/j.biocon.2010.02.009.

Beschta RL, Ripple WJ (2009) Large predators and trophic cascades in terrestrial ecosystems of the western United States. Biol Conserv 142:2401-2414. https://doi.org/10.1016/j.biocon.2009.06.015.

Brown ED, Williams BK (2016) Ecological integrity assessment as a metric of biodiversity: are we measuring what we say we are? Biodivers Conserv 25: 1011-1035.

Brownlie S, King N, Treweek J (2013) Biodiversity tradeoffs and offsets in impact assessment and decision making: can we stop the loss? Impact Assess Proj Apprais 31:24-33. https://doi.org/10.1080/14615517.2012.736763.

Callicott JB, Mumford K (1997) Ecological sustainability as a conservation concept. Conserv Biol 11:32-40. https://doi.org/10.1046/j.1523-1739.1997.95468.x.

Cámara de Diputados del Honorable Congreso de la Unión (2017) Ley General del Equilibrio Ecológico y la Protección al Ambiente. Diario Oficial la Federación. 130 pp. México, Distrito Federal. México

Canter LW, Atkinson SF (2011) Multiple uses of indicators and indices in cumulative effects assessment and management. Environ Impact Assess Rev 31:491-501. https://doi.org/10.1016/j.eiar.2011.01.012.

Cao F, Ge Y, Wang J (2014) Spatial data discretization methods for geocomputation. Int J Appl Earth Obs Geoinf 26:432-440. https://doi.org/10. 1016/j.jag.2013.09.005.

Capmourteres V, Anand M (2016) Assessing ecological integrity: a multi-scale structural and functional approach using structural equation modeling. Ecol Indic 71:258-269. https://doi.org/10.1016/j.ecolind.2016.07.006.

Cowell DW (1998) Ecological landscape planning techniques for biodiversity and sustainability. Environ Manag Health 9:72-78. https://doi.org/10.1108/ 09566169810211177.

Crooks KR, Burdett CL, Theobald DM et al (2011) Global patterns of fragmentation and connectivity of mammalian carnivore habitat. Philos Trans R Soc Lond Ser B Biol Sci 366:2642-2651. https:/doi.org/10.1098/rstb.2011.0120.

D’Amico M, Périquet S, Román J, Revilla E (2016) Road avoidance responses determine the impact of heterogeneous road networks at a regional scale. J Appl Ecol 53:181-190. https://doi.org/10.1111/1365-2664.12572.

Dale VH, Beyeler SC (2001) Challenges in the development and use of ecological indicators. Ecol Indic 1:3-10. https://doi.org/10.1016/S1470-160X(01)00003-6.

de Souza JC, da Silva RM, Gonçalves MPR et al (2018) Habitat use, ranching, and human-wildlife conflict within a fragmented landscape in the Pantanal, Brazil. Biol Conserv 217:349-357. https://doi.org/10.1016/j. biocon.2017.11.019.

Dellinger JA, Proctor C, Steury TD et al (2013) Habitat selection of a large carnivore, the red wolf, in a human-altered landscape. Biol Conserv 157:324330. https://doi.org/10.1016/j.biocon.2012.09.004.

Dobson A (2005) Monitoring global rates of biodiversity change: challenges that arise in meeting the convention on biological diversity (CBD) 2010 goals. Philos Trans R Soc B Biol Sci 360:229-241. https://doi.org/10.1098/ rstb.2004.1603.

Dobson A, Lodge D, Alder J et al (2011) Habitat loss, trophic collapse, and the decline of ecosystem services. Ecology 87:1915-1924.

Ewers RM, Marsh CJ, Wearn OR (2010) Making statistics biologically relevant in fragmented landscapes. Trends Ecol Evol 25:699-704. https://doi.org/10.1016/ j.tree.2010.09.008

Forman RTT, Alexander LE (1998) Roads and their major ecological effects. Annu Rev Ecol Syst 29:207-231. https://doi.org/10.1146/annurev.ecolsys.29.1.207.

Geaur Rahman M, Zahidul Islam M (2016) Discretization of continuous attributes through low frequency numerical values and attribute interdependency. Expert Syst Appl 45:410-423. https://doi.org/10.1016/j. eswa.2015.10.005.

Geneletti D (2003) Biodiversity impact assessment of roads : an approach based on ecosystem rarity. Environ Impact Assess Rev 23:343-365. https://doi.org/ 10.1016/S0195-9255(02)00099-9. 
Geneletti D (2004) Using spatial indicators and value functions to assess ecosystem fragmentation caused by linear infrastructures. Int J Appl Earth Obs Geoinf 5:1-15. https://doi.org/10.1016/j.jag.2003.08.004.

Geneletti D (2006) Some common shortcomings in the treatment of impacts of linear infrastructures on natural habitat. Environ Impact Assess Rev 26:257267. https://doi.org/10.1016/j.eiar.2005.10.003.

Gontier M, Balfors B, Mörtberg U (2006) Biodiversity in environmental assessment-current practice and tools for prediction. Environ Impact Assess Rev 26:268-286. https://doi.org/10.1016/j.eiar.2005.09.001.

Holderegger R, Di Giulio M (2010) The genetic effects of roads: a review of empirical evidence. Basic Appl Ecol 11:522-531. https://doi.org/10.1016/j. baae.2010.06.006.

Huang X, Schneider A, Friedl MA (2016) Mapping sub-pixel urban expansion in China using MODIS and DMSP/OLS nighttime lights. Remote Sens Environ 175:92-108. https://doi.org/10.1016/j.rse.2015.12.042.

Jax, K. (2010). Ecosystem Functioning (Ecology, Biodiversity and Conservation). Cambridge: Cambridge University Press. https://doi.org/10.1017/ CBO9780511781216.

Jędrzejewski W, Boede EO, Abarca M et al (2017) Predicting carnivore distribution and extirpation rate based on human impacts and productivity factors; assessment of the state of jaguar (Panthera onca) in Venezuela. Biol Conserv 206:132-142. https://doi.org/10.1016/j.biocon. 2016.09.027.

Kandziora M, Burkhard B, Müller F (2013) Interactions of ecosystem properties, ecosystem integrity and ecosystem service indicators-a theoretical matrix exercise. Ecol Indic 28:54-78. https://doi.org/10.1016/j. ecolind.2012.09.006.

Karlson M, Mörtberg U, Balfors B (2014) Road ecology in environmental impact assessment. Environ Impact Assess Rev 48:10-19. https://doi.org/10.1016/j. eiar.2014.04.002.

Karr JR (1990) Biological integrity and the goal of environmental legislation: lessons for conservation biology. Conserv Biol 4:244-250.

Krofel M, Hočevar L, Allen ML (2017) Does human infrastructure shape scent marking in a solitary felid? Mamm Biol 87:36-39. https://doi.org/10.1016/j. mambio.2017.05.003.

Laurance WF, Goosem M, Laurance SGW (2009) Impacts of roads and linear clearings on tropical forests. Trends Ecol Evol 24:659-669. https://doi.org/10. 1016/j.tree.2009.06.009.

Levin SA (2005) Self-organization and the emergence of complexity in ecological systems. Bioscience 55:1075. https://doi.org/10.1641/00063568(2005)055[1075:SATEOC]2.0.CO;2

Liu H, Hussain F, Tan CL, Dash M (2002) Discretization: an enabling technique. Data Min Knowl Disc 6:393-423. https://doi.org/10.1023/A:1016304305535.

Lundberg J, Moberg F (2003) Mobile link organisms and ecosystem functioning: implications for ecosystem resilience and management. Ecosystems 6:87-98. https://doi.org/10.1007/s10021-002-0150-4.

Ma T, Zhou C, Pei T et al (2012) Quantitative estimation of urbanization dynamics using time series of DMSP/OLS nighttime light data: a comparative case study from China's cities. Remote Sens Environ 124:99-107. https://doi.org/ 10.1016/j.rse.2012.04.018.

Ma T, Zhou Y, Zhou C et al (2015) Night-time light derived estimation of spatio-temporal characteristics of urbanization dynamics using DMSP/OLS satellite data. Remote Sens Environ 158:453-464. https://doi.org/10.1016/j. rse.2014.11.022

Miller BJ, Harlow HJ, Harlow TS et al (2012) Trophic cascades linking wolves (Canis lupus), coyotes (Canis latrans), and small mammals. Can J Zool 90:7078. https://doi.org/10.1139/z11-115.

Mora F (2017a) Nation-wide indicators of ecological integrity in Mexico: the status of mammalian apex-predators and their habitat. Ecol Indic 82. https:// doi.org/10.1016/j.ecolind.2017.06.030.

Mora F (2017b) A structural equation modeling approach for formalizing and evaluating ecological integrity in terrestrial ecosystems. Eco Inform 41:74-90. https://doi.org/10.1016/j.ecoinf.2017.05.002.

Nojavan AF, Qian SS, Stow CA (2017) Comparative analysis of discretization methods in Bayesian networks. Environ Model Softw 87:64-71. https://doi. org/10.1016/j.envsoft.2016.10.007.

Nuttle T, Bredeweg B, Salles P, Neumann M (2009) Representing and managing uncertainty in qualitative ecological models. Eco Inform 4:358-366. https:// doi.org/10.1016/j.ecoinf.2009.09.004.

Odum HT (1988) Self-organization, transformity, and information. Science 242 $1132-1139$
Parrish JD, Braun DP, Unnasch RS, Parrish JD, Braun DP, Unnasch RS (2003) Are we conserving what we say we are? Measuring ecological integrity within protected areas. Bioscience 53:851-860. https://doi.org/10.1641/00063568(2003)053[0851:AWCWWS]2.0.CO;2.

Rempel RS, Naylor BJ, Elkie PC et al (2016) An indicator system to assess ecological integrity of managed forests. Ecol Indic 60:860-869. https://doi. org/10.1016/j.ecolind.2015.08.033.

Reza MIH, Abdullah SA (2011) Regional index of ecological integrity: a need for sustainable management of natural resources. Ecol Indic 11:220-229. https:// doi.org/10.1016/j.ecolind.2010.08.010.

Riitters KH, Wickham JD, Neill RVO et al (2002) Fragmentation of continental fragmentation united forests. Ecosystems 5:815-822. https://doi.org/10.1007/ s10021002-0209-2.

Ripple WJ, Beschta RL (2004) Wolves and the ecology of fear: can predation risk structure ecosystems? Bioscience 54:755. https://doi.org/10.1641/00063568(2004)054[0755:WATEOF]2.0.CO;2.

Ripple WJ, Estes JA, Beschta RL et al (2014) Status and ecological effects of the world's largest carnivores. Science 343:1241484. https://doi.org/10.1126/ science. 1241484

Ritchie EG, Elmhagen B, Glen AS et al (2012) Ecosystem restoration with teeth: what role for predators? Trends Ecol Evol 27:265-271. https://doi.org/10. 1016/j.tree.2012.01.001.

Roche PK, Campagne CS (2017) From ecosystem integrity to ecosystem condition: a continuity of concepts supporting different aspects of ecosystem sustainability. Curr Opin Environ Sustain 29:63-68. https://doi.org/ 10.1016/j.cosust 2017.12.009

SEMARNAT (2010) Norma Oficial Mexicana NOM-059-SEMARNAT-2010, Mexico D.F..

Sergio F, Caro T, Brown D et al (2008) Top predators as conservation tools: ecological rationale, assumptions, and efficacy. Annu Rev Ecol Evol Syst 39:119. https://doi.org/10.1146/annurev.ecolsys.39.110707.173545.

Sergio F, Newton I, Marchesi L, Pedrini P (2006) Ecologically justified charisma: preservation of top predators delivers biodiversity conservation. J Appl Ecol 43:1049-1055. https://doi.org/10.1111/j.1365-2664.2006.01218.x.

Sih A, Gunnar B, Luikart G (2000) Habitat loss: ecological , evolutionary and genetic consequences. TREE 15:132-134.

Stockwell D, Peters D (1999) The GARP modelling system: problems and solutions to automated spatial prediction. Int J Geogr Inf Sci 13:143-158. https://doi.org/10.1080/136588199241391.

Swift TL, Hannon SJ (2010) Critical thresholds associated with habitat loss: a review of the concepts, evidence, and applications. Biol Rev 85:35-53. https://doi.org/10.1111/j.1469-185X.2009.00093.x.

Thompson I (1999) Ecological sustainability and integrity: concepts and approaches. J Environ Plan Manag 42:136-137. https://doi.org/10.1007/97894-017-1337-5.

Tierney GL, Faber-Langendoen D, Mitchell BR et al (2009) Monitoring and evaluating the ecological integrity of forest ecosystems. Front Ecol Environ 7: 308-316. https://doi.org/10.1890/070176.

Treweek J (1996) Ecology and environmental impact assessment. J Appl Ecol 33: 191-199.

Tucker MA, Böhning-Gaese K, Fagan WF et al (2018) Moving in the Anthropocene: global reductions in terrestrial mammalian movements. Science 359:466-469. https://doi.org/10.1126/science.aam9712.

Uusitalo L (2007) Advantages and challenges of Bayesian networks in environmental modelling. Ecol Model 203:312-318. https://doi.org/10.1016/j. ecolmodel.2006.11.033.

Valiente-Banuet A, Aizen MA, Alcántara JM et al (2015) Beyond species loss: the extinction of ecological interactions in a changing world. Funct Ecol 29:299307. https://doi.org/10.1111/1365-2435.12356.

Wallach AD, Ripple WJ, Carroll SP (2015) Novel trophic cascades: apex predators enable coexistence. Trends Ecol Evol 30:146-153. https://doi.org/10.1016/j. tree.2015.01.003

Winter S, Fischer HS, Fischer A (2010) Relative quantitative reference approach for naturalness assessments of forests. For Ecol Manag 259:1624-1632. https:// doi.org/10.1016/j.foreco.2010.01.040.

Wurtzebach Z, Schultz C (2016) Measuring ecological integrity: history, practical applications, and research opportunities. Bioscience 66:446-457. https://doi. org/10.1093/biosci/biw037.

Zarco-González MM, Monroy-Vilchis O, Alaníz J (2013) Spatial model of livestock predation by jaguar and puma in Mexico: conservation planning. Biol Conserv 159:80-87. https://doi.org/10.1016/j.biocon.2012.11.007. 